I N S T I T U T O

DE

M E D I C I N A

T R O P I C A L

DE

SÃO PAULO

JOURNAL OF THE SÃO PAULO INSTITUTE OF TROPICAL MEDICINE

${ }^{1}$ Universidade Federal do Ceará, Faculdade de Medicina, Fortaleza, Ceará, Brazil

2Universidade de Fortaleza, Curso de Medicina, Fortaleza, Ceará, Brazil

Correspondence to: Malena Gadelha Cavalcante

Universidade do Ceará, Faculdade de Medicina, Rua Ines Dantas de Menezes, 333, Castelão, CEP 60867-570, Fortaleza, CE, Brazil

Tel: +55 $8599757-5761$

E-mail: malenagadelha@ hotmail.com

Received: 27 November 2020

Accepted: 19 March 2021

\section{Death-related factors in HIV/AIDS patients undergoing hemodialysis in an intensive care unit}

\author{
Malena Gadelha Cavalcante ${ }^{(1}$, Matheus de Sá Roriz Parente ${ }^{(1)}$, Pedro \\ Eduardo Andrade de Carvalho Gomes ${ }^{(1)}$, Gdayllon Cavalcante Meneses ${ }^{(1)} 1$, \\ Geraldo Bezerra da Silva Júnior ${ }^{(1,2}$, Roberto da Justa Pires Neto ${ }^{(1)}$, \\ Elizabeth De Francesco Daher ${ }^{(1)}$
}

\section{ABSTRACT}

HIV-infected patients are at high risk for developing critical diseases, including opportunistic infections (OI), with consequent admission in intensive care units (ICU). Renal disfunctions are risk factors for death in HIV/AIDS patients, and survival rates in patients undergoing hemodialysis are smaller than the ones observed in the general population. In this context, this study aimed to investigate death-related factors in HIV/AIDS patients in an intensive care setting. This is a retrospective cross-sectional study performed through the analysis of medical records from 271 HIV/AIDS-diagnosed patients hospitalized in an intensive care unit of an infectious disease hospital, in Fortaleza, Ceara State, Brazil. Patients were divided into two groups: those who underwent dialysis during hospitalization and those who did not. Clinical and demographic parameters that could be associated with death were evaluated. Results indicated a prevalence of death of $19.1 \%$ (CI 95\%: 14.8-24.3). The median age of patients was 47 years, with a male predominance (71.3\%). The main causes of admission were pulmonary tuberculosis $(16.9 \%)$, followed by neurotoxoplasmosis $(14.9 \%)$. In the bivariate analysis, for those that did not undergo dialysis, age, fever, dyspnea, oliguria, disorientation, kidney injury, use of lamivudine and efavirenz, length of hospitalization, CD4 count, WBC count, platelet count, urea, sodium and LDH levels were the associated variables. In those who needed dialysis, the use of stavudine, abacavir and ritonavir, and the length of hospitalization were associated factors. Renal toxicity by the antiretroviral agents and length of hospitalization increased the risk of death among HIV patients under dialysis.

KEYWORDS: HIV. AIDS. Intensive Care Unit. Death. Dialysis. Renal failure.

\section{INTRODUCTION}

According to the United Nations Program on HIV/AIDS (UNAIDS), there were 38 million people with human immunodeficiency virus (HIV) and 690 thousand deaths related to the acquired immunodeficiency syndrome (AIDS) in the world, in $2019^{1}$. Despite the advances promoted by the antiretroviral therapy (ART), including substantial increase in life expectancy, turning HIV from a fatal disease to a chronic condition, the disease remains a public health challenge worldwide ${ }^{2}$.

Patients infected with HIV are at high risk for developing critical diseases due to their advanced immunosuppression, increased susceptibility to tuberculosis and bacterial sepsis and underlying comorbidities, which are associated with their more frequent admission to intensive care units (ICUs) $)^{3,4}$. Other leading 
causes of hospitalization include drug toxicity, hepatitis $\mathrm{B}$ or $\mathrm{C}$ coinfection, cardiomyopathy, renal injury, chronic pulmonary disease and cirrhosis ${ }^{3}$.

Renal impairment, mainly represented by chronic kidney disease and end-stage renal disease, is a risk factor for death among patients with HIV/AIDS ${ }^{5,6}$. Survival rates in patients undergoing hemodialysis are smaller than the ones observed in the general population ${ }^{7}$.

Considering the reduced number of studies with critical HIV patients in Brazil and the high mortality among hospitalized individuals, the present study aimed to investigate risk factors for death in patients with HIV/AIDS undergoing hemodialysis in an intensive care setting ${ }^{4,8}$.

\section{MATHERIALS AND METHODS}

This is a retrospective cross-sectional study performed through the analysis of medical records from patients diagnosed with HIV/AIDS, who were admitted to the Intensive Care Unit (ICU) of an infectious disease hospital in Fortaleza, Ceara State, Brazil. Medical records from all HIV/AIDS patients admitted to the ICU from January 2013 to November 2017, aged 18 years or over, regardless of the hospitalization cause, with positive serological tests to HIV (ELISA and Western Blot), in accordance with the recommendation of the Brazilian Ministry of Health. Medical records from cases in which it was not possible to identify the clinical outcome were excluded. The sample consisted of 271 patients who were divided into two different groups: those who underwent dialysis $(\mathrm{n}=33)$ and those who did not $(n=238)$. Each of these groups was stratified according to the evolution to death or not.

Data collection was carried out by a team composed of a researchers previously trained in filling out the research form designed to assess the following clinical and demographic parameters available in medical records: age, gender, main signs and symptoms at the time of hospital admission (fever, chills, cough, dyspnea, diarrhea, vomiting, weight loss, asthenia, myalgia, anorexia, oliguria, disorientation, seizures, headache, chest pain, abdominal pain and low back pain), aside from presence of renal injury, coinfection with $\mathrm{HBV}$ or $\mathrm{HCV}$, opportunistic diseases, use of ART, habitsand length of hospitalization. There was also a data collection related to the following laboratory tests: CD4 count, viral load, hemoglobin, hematocrit, white blood cells (WBC) count, platelets count, serum urea, serum creatinine, plasma sodium, plasma potassium, lactic dehydrogenase (LDH), aspartate aminotransferase (AST) and alanine aminotransferase (ALT).

Statistical analysis was performed using the Statistical Package for Social Science (SPSS), version 20.0 for
Windows (IBM Corp., Armonk, New York, USA). Death during treatment was defined as the study outcome. This variable was verified by the stratification of dialysis in order to identify the possible effect of dialysis on mortality. The predictive variables of the study were related to sociodemographic characteristics, comorbidities, previous and current ART and laboratory tests. All variables were collected through medical records.

For data analyses, the nominal variables were described using simple and relative frequencies, and, for numerical variables, the median and the interquartile range were presented. The predictor variables were compared based on the occurrence of death or not, using the chi-square test (for nominal variables) or the Wilcoxon test (for numerical variables). A P-value $<0.05$ was considered statistically significant. This same process was performed for the stratification by dialysis. Crude and adjusted odds ratios (ORs) were calculated, as well as 95\% confidence intervals (CIs).

For the regression analysis, the logistic model was used. Firstly, the variables with a p-value $<0.20$ were used in the bivariate analysis and by a step-by-step model, and the exclusion of variables whose $p$-values were $>0.05$. The final model was adjusted for the variables with a p-value $<$ 0.05 . For the stratified analysis, the significant variables of the bivariate analysis were selected and the same previous method was adopted for the final adjustment. It should be noted that in all regression models the total CD4 count was not used as a variable because the models did not converge.

The research was submitted to and approved by the Medical Ethics Committee of Hospital Sao Jose of Infectious Diseases, under the process $\mathrm{N}^{\circ}$ 284.915.

\section{RESULTS}

The prevalence of death among all the patients was 19.1\% (95\% CI: 14.8-24.3). Most of the patients were male (196 [71.3\%]), and the median age was 47 years. Only 208 (76.7\%) used ART, and lamivudine was the most commonly used drug (195 [80.9\%]). The main cause of hospitalization was pulmonary tuberculosis (50 [16.9\%]), followed by neurotoxoplasmosis (50 [14.9\%]). The most frequent symptoms were fever (174 [63.7\%]) and chills (234 [86.0\%]). Diabetes mellitus was the most prevalent comorbidity (27 [10.0\%]). In addition, $33(18.2 \%)$ patients underwent hemodialysis.

When stratified by the need for hemodialysis, there were differences between the two group. For patients who did not undergo hemodialysis, age, fever, dyspnea, oliguria, disorientation, kidney injury, use of lamivudine and efavirenz, length of hospitalization, CD4 count, WBC count, 
platelet count, urea, sodium and LDH were the associated variables. For patients who underwent hemodialysis, the use of stavudine, abacavir and ritonavir, as well as the length of hospitalization were associated factors (Tables 1 and 2).

For patients who did not undergo dialysis, each increment of one year of age, increased the chances of death by $6 \%$ (95\% CI: 1.03-1.10). Dyspnea was associated with a 3.9-fold risk of death (95\% CI: 1.48-10.31). Concerning laboratory parameters, an increase in the WBC was associated with a slightly increased risk of death $(p=0.03)$, and an increase in the platelet count decreased the risk of death by $1 \%$ (95\% CI: 0.998-0.999). Among patients who required hemodialysis, the logistic regression model did not reach convergence when the use of stavudine was present,

Table 1 - Demographic characteristics and factors associated with death stratified by the need of undergoing dialysis.

\begin{tabular}{|c|c|c|c|c|c|c|c|c|}
\hline & \multicolumn{4}{|c|}{$\begin{array}{l}\text { Patients who needed hemodialysis } \\
\qquad \mathrm{N}=33\end{array}$} & \multicolumn{4}{|c|}{$\begin{array}{l}\text { Patients who did not need hemodialysis } \\
\qquad \mathrm{N}=238\end{array}$} \\
\hline & $\mathrm{N}(\%)$ & $p$ & OR & IC & $\mathrm{N}(\%)$ & $p$ & OR & IC \\
\hline Age (years) & $61(50-66)$ & 0.983 & 1.05 & $1.02-1.08$ & $61(56-68)$ & $<0.001$ & 1.00 & $0.94-1,06$ \\
\hline Gender (male) & $18(72.0)$ & 0.601 & 1.08 & $0.45-2.57$ & $21(12.4)$ & 0.857 & 1.54 & $0.28-8.25$ \\
\hline Fever & $12(63.2)$ & 0.341 & 2.91 & $1.06-7.95$ & $24(15.6)$ & 0.030 & 0.46 & $0.10-2.27$ \\
\hline Dyspnea & $12(75.0)$ & 0.520 & 3.81 & $1.67-8.71$ & $18(21.2)$ & 0.001 & 1.63 & $0.36-7.38$ \\
\hline Oliguria & $6(50.0)$ & 0.063 & 8.24 & $1.57-43.01$ & $3(50.0)$ & 0.003 & 0.23 & $0.04-1.13$ \\
\hline Disorientation & $8(80.0)$ & 0.396 & 3. 90 & 1. $72-8.82$ & $13(26.5)$ & 0.001 & 2.13 & $0.36-12.53$ \\
\hline Alcoholism & $8(66.7)$ & 0.775 & 0.78 & $0.32-1.88$ & $8(9.6)$ & 0.584 & 0.8 & $0.17-3.68$ \\
\hline Smoking & $4(66.7)$ & 0.858 & 0.55 & $0.20-1.54$ & $5(7.5)$ & 0.255 & 0.84 & $0.13-5.60$ \\
\hline Renal failure & $16(64.0)$ & 0.208 & 4.23 & $1.63-10.99$ & $8(32.0)$ & 0.002 & 0.25 & $0.02-2.40$ \\
\hline Opportunistic diseases & $12(70.6)$ & 0.909 & 0.48 & $0.21-1.08$ & $12(8.8)$ & 0.072 & 1.10 & $0.25-4.81$ \\
\hline
\end{tabular}

Table 2 - Antiretroviral therapy and laboratory tests associated with death, stratified by the need of undergoing dialysis.

\begin{tabular}{|c|c|c|c|c|c|c|c|c|}
\hline & $N(\%)$ & $p$ & OR & IC & $N(\%)$ & $p$ & OR & IC \\
\hline ARVT & $13(61.9)$ & 0.198 & 0.27 & $0.12-0.62$ & $16(8.6)$ & 0.001 & 0.33 & $0.06-1.87$ \\
\hline ARVT time (days) & $36(1-158)$ & 0.813 & 1.00 & $0.99-1.00$ & $12(0-73)$ & 0.679 & 0.99 & $0.98-1.00$ \\
\hline 3TC & $9(50.0)$ & 0.034 & 0.23 & $0.09-0.55$ & $16(9.1)$ & $<0.001$ & 0.11 & $0.02-1.06$ \\
\hline$A B C$ & $2(28.6)$ & 0.029 & 0.47 & $0.06-3.80$ & $1(7.7)$ & 0.472 & 0.13 & $0.02-0.91$ \\
\hline TDF & $6(54.5)$ & 0.268 & 0.56 & $0.24-1.31$ & $10(9.9)$ & 0.179 & 0.4 & $0.08-2.06$ \\
\hline LPV & $3(100.0)$ & 0.166 & 1.70 & $0.57-5.05$ & $5(20.8)$ & 0.332 & $\star \star \star *$ & *** \\
\hline RTV & $2(28.6)$ & 0.017 & 1.26 & $0.39-4.02$ & $4(16.7)$ & 0.702 & 0.11 & $0.01-0.77$ \\
\hline EFZ & $5(55.6)$ & 0.573 & 0.40 & $0.18-0.93$ & $10(8.8)$ & 0.031 & 0.62 & $0.12-3.22$ \\
\hline NVP & $2(100.0)$ & 0.284 & *** & $* * *$ & $0(0.0)$ & 0.203 & $* * *$ & *** \\
\hline CD4 (absolute) & $143(51-478)$ & 0.782 & 1,002 & $1,0003-1,004$ & $363(232-517)$ & 0.018 & 0.99 & $0.99-1.00$ \\
\hline VC (absolute) & $364(0-70,814)$ & 0.664 & 0,99 & $0,99-1,00$ & $305(0-3.778)$ & 0.284 & 0.99 & $0.99-1.00$ \\
\hline $\mathrm{Na}^{+}(\mathrm{mEq} / \mathrm{L})$ & $137(130-144)$ & 0.817 & 1,08 & $1,01-1,16$ & $139(132-143)$ & 0.022 & 1.00 & $0.93-1.10$ \\
\hline $\mathrm{K}^{+}(\mathrm{mEq} / \mathrm{L})$ & $4.7(3.9-5.7)$ & 0.293 & 1,39 & $0,88-2,19$ & $4.1(3.5-4.55)$ & 0.150 & 1.49 & $0.70-3.13$ \\
\hline WBCs $/ \mathrm{mm}^{3}$ & $6,780(2,710-12,400)$ & 0.556 & 1,00007 & $1,00001-1,001$ & $7,590(5,220-11,500)$ & 0.0009 & 1.00 & $0.99-1.00$ \\
\hline Lymphocytes $/ \mathrm{mm}^{3}$ & $790(290-1,310)$ & 0.335 & 0,99 & $0,99-1,00$ & $370(11-804)$ & 0.361 & 0.99 & $0.99-.00$ \\
\hline Platelets $/ \mathrm{mm}^{3}$ & $138(79,000-199,000)$ & 0.458 & 0,994 & 0,990-0,999 & $172,000(70,500-218,000)$ & 0,012 & 0.99 & $0.99-1.00$ \\
\hline LDL (mg/dL) & $1,151(616-1,749)$ & $0, .061$ & 1,005 & $1,0002-1,001$ & $610(429-850)$ & 0,040 & 1.00 & $0.99-1.00$ \\
\hline Ureia (mg/dL) & $104(51-185)$ & 0.936 & 1,02 & $1,01-1,04$ & $54(35-91)$ & $<0,001$ & 1.00 & $0.99-1.00$ \\
\hline Creatinine (mg/dL) & $2.4(2-6.8)$ & 0.880 & 1,45 & $0,95-2,20$ & $1.0(0.7-1.7)$ & 0.086 & 0.98 & $0.81-1.18$ \\
\hline Length of Hospitalization (days) & $7(14-21)$ & 0.028 & 0,95 & 0,91-0,99 & $11(5-13)$ & 0.035 & 0.95 & 0.91-0.99 \\
\hline
\end{tabular}

ARVT = antiretroviral therapy; AZT = zidovudine; $3 T \mathrm{C}=$ lamivudine; $\mathrm{d} 4 \mathrm{~T}=$ stavudine; $\mathrm{ABC}=$ abacavir; $\mathrm{TDF}=$ tenofovir; $\mathrm{LPV}=$ lopinavir; $\mathrm{ATV}=$ atazanavir; IDV = indinavir; NFV = nelfinavir; RTV = ritonavir; $E F Z=$ efavirenz; NVP = nevirapine; $D M=$ diabetes mellitus; $H C V=$ hepatitis $C$ virus; $H B V=$ hepatitis $B$ virus; $\mathrm{VC}=$ viral charge; $\mathrm{Hb}=$ hemoglobin; $\mathrm{HTC}=$ hematocrit; $\mathrm{WBC}=$ white blood cells; $\mathrm{LDL}=$ low density lipoproteins; $\mathrm{Ur}=\mathrm{urea} ; \mathrm{Cr}=\mathrm{creatinine}$; $\mathrm{AST}=$ aspartate aminotransferase; $\mathrm{ALT}=$ alanine aminotransferase. 
so it was removed. Considering the remaining variables, the length of the treatment was the only variable that remained associated. Thus, the increase of one day in the length of hospital stay reduced the chances of death by $5 \%$ (95\% CI: 0.90-0.99) (Table 3).

Table 3 - Logistic regression analysis on the chances of death for the studied sample according to the need of dialysis.

\begin{tabular}{lccc}
\hline \multicolumn{4}{c}{ Patients who did not undergo dialysis } \\
\hline Age & OR & Cl 95\% & P-value \\
Dyspnea & 1.06 & $1.03-1.10$ & $<0.001$ \\
WBCs count & 3.90 & $1.48-10.31$ & 0.01 \\
Platelets count & 1.00001 & $1.000005-1.0001$ & 0.03 \\
\hline \multicolumn{4}{c}{ Patients who underwent dialysis } \\
\hline OB & Cl 95\% & P-value \\
\hline OBC & 0.99 & $0.998-0.999$ & 0.01 \\
RTV & 0.22 & $0.02-2.62$ & 0.23 \\
Length of hospitalization & 0.95 & $0.01-1.24$ & 0.08 \\
\hline
\end{tabular}

\section{DISCUSSION}

In patients who did not need hemodialysis, age, fever, dyspnea, oliguria, disorientation, kidney injury, use of lamivudine and efavirenz, length of hospitalization, WBC count, platelet count, urea, sodium and LDH were associated factors. For the ones who needed hemodialysis, the use of stavudine, abacavir and ritonavir, and the length of hospitalization were factors associated with death.

The overall death rate in the present study was twice as high as that found in a previous cohort study conducted in the Southeast region of $\mathrm{Brazil}^{9}$, however it is lower than the general prevalence found in the Northeast region $(22 \%)^{10}$. Despite the free access to ART nationwide, late diagnosis and difficulties in accessing the therapy are still frequent, which result in a greater risk for severe immunodepression and, consequently, increasing the chances of ICU hospitalization.. Therefore, there is a need to improve public policies aimed at the prompt diagnosis and initiation of ART in HIV/AIDS patients in the country's Northeast region, as a way to guarantee the early identification of cases and thus preventing severe immunodepression, opportunistic infections, hospitalizations and death.

This study demonstrated a predominance of elderly patients in the ICU and association between the increasing of age and death. This confirms a trend of life expectancy increment among patients with HIV, which results in an increasing proportion of infected patients over the age of 50 years, especially in low-income countries. It also stands out the greater chance of HIV infection in the elderly ${ }^{11}$.

This finding is an alert for health professionals to screen HIV among the elderly at the time of admission to the ICU, prior to hospitalization, thus enabling an early diagnosis and the beginning of treatment in a timely manner, mainly because the symptoms of AIDS may resemble manifestations that are common to aging, as well as other comorbidities and chronic conditions ${ }^{12}$.

In addition, some evidence points to a reduced survival of elderly people after the HIV diagnosis and an increased risk of disease progression among those with suboptimal adherence to treatment ${ }^{13}$. Therefore, it is necessary to reinforce the quality of interdisciplinary outpatient monitoring in this age group, so as to recognize factors associated with non-adherence to treatment and to provide an adequate management of associated comorbidities.

Pulmonary tuberculosis stood out as the main cause of admission to the ICU, in line with the literature ${ }^{14}$. Approximately 1 to $3 \%$ of HIV/tuberculosis coinfection cases need to be referred to the Intensive Care Unit, with death rates ranging from 2 to $67 \%$. Interventions are needed to prevent and control tuberculosis cases, such as early diagnosis, case control and effective treatment, with a focus on reducing the impact of this coinfection on the mortality of people with $\mathrm{HIV}^{16}$.

Concerning symptoms that were related to death among patients who did not need hemodialysis, fever, dyspnea, and disorientation are associated with opportunistic respiratory diseases, commonly found in patients who need medical assistance in intensive care settings ${ }^{14}$. Oliguria was also associated with death in this group, which may be related to the development of kidney injuries, a worsening prognosis factor in critically ill patients ${ }^{3}$. No other symptoms associated with greater chances of death were identified among patients who needed hemodialysis.

The occurrence of non-transmissible comorbidities, such as diabetes, among the investigated population also corresponds to the literature, being related to chronic inflammation in patients with HIV due to chronic immune activation, treatment failure, as well as socioeconomic and behavioral factors in this population ${ }^{17-19}$. It is worth mentioning that preexisting chronic conditions can make HIV patients who are critically ill, more susceptible to kidney disease during their ICU stay ${ }^{20}$.

Given the risk posed by the variety of chronic noninfectious diseases to which patients with HIV are exposed, additional care is needed, focusing on improving the lifestyle of this population, providing a better control of sociodemographic and behavioral factors, in addition to other chronic comorbidities, with integration between specialized HIV care services and primary health care ones ${ }^{21}$. 
CD4 count was associated with death among patients who did not need hemodialysis, in agreement with previous studies carried out in critically ill HIV patients ${ }^{22-24}$. This association was already expected, since decreasing levels of CD4 cells reflect a weaker immune status, being associated with an increased risk of opportunistic infections with great clinical severity. However, this factor was not associated with death among HIV patients on hemodialysis, diverging from a previous retrospective cohort study carried out in an outpatient service in Cameroon in which severe immunodepression was associated with a decrease in the survival rate among those patients ${ }^{6}$. This difference may be related to the fact that, in the present study, hemodialysis has probably started during the ICU stay.

The length of hospitalization was a contributing factor to death in both strata, with a median of 7 days for patients who needed hemodialysis and died, and 11 days for patients who did not need hemodialysis, similar to results found in other studies ${ }^{25,26}$. This is an important indicator for assessing the quality of care provided to ICU patients, therefore, future research should assess HIV patients' care in this scenario.

In view of this finding, it is necessary to reflect on the difficulties of access of HIV-positive patients to ICUs within the scope of the Unified Health System (SUS), which can prolong the length of stay and the severity of the clinical condition, increasing the risk of unfavorable outcomes.

The use of antiretroviral therapy improved survival among patients who did not undergo dialysis. However, it did not follow the same trend among patients who required it. This finding may be related to the fact that the beneficial effects of ART are attenuated by a greater severity of critical illnesses ${ }^{27}$. On the other hand, the potentially toxic effect of ART stands out, which can trigger the inflammatory syndrome of immune reconstitution, leading to death ${ }^{28}$.

These results highlight the challenges of using antiretrovirals in critically ill patients, such as dose control, absorption problems, recognition of drug interactions, identification of toxic effects and suspension of antiretroviral treatment ${ }^{29}$. Therefore, specialists need to balance the risks and benefits of continuous use of antiretrovirals among critically ill patients.

In the present study, the use of lamivudine and efavirenz, which are drugs with low renal toxicity, was related to death among patients that did not undergo dialysis. The literature points out that these drugs have adverse effects (dermatological, gastrointestinal symptoms and neuropsychiatric disorders) that may lead the patient to discontinue the treatment ${ }^{30}$. Consequently, these patients are more susceptible to opportunistic infections, hospitalization and death.
Among those who underwent dialysis, the use of stavudine, abacavir and ritonavir was significantly associated with a higher risk of death. In the literature, these antiretroviral drugs are identified among those that can cause kidney injuries ${ }^{31}$. The use of these drugs may justify the need for hemodialysis, which in turn is a factor that has been shown to reduce the survival rate of critically ill patients ${ }^{7}$.

The limitations of this study include its retrospective design, missing data in several medical records and its local character, which limits the generalization of results.

\section{AUTHORS' CONTRIBUTIONS}

MGC, EDF, GBSJ e RJPN participated in the conception, design and writing of the article. MSRP, PEACG, GCM participated in the collection and interpretation of the data. All authors participated in the critical review and approval of the version to be published.

\section{REFERENCES}

1. Joint United Nations Programme on HIV/AIDS. Global AIDS update: 2020. Geneva: UNAIDS; 2020. [cited 2021 Mar 19]. Available from: https://www.unaids.org/sites/default/files/ media_asset/2020_global-aids-report_en.pdf

2. Silva Junior GB, Parente Filho SL, Soares DS, Alencar RN, Peixoto TT, Nogueira IS, et al. Acute kidney injury and other factors associated with mortality in HIV-infected patients. Rev Assoc Med Bras. 2018;64:509-17.

3. Barbier F, Mer M, Szychowiak P, Miller RF, Mariotte E, Galicier $\mathrm{L}$, et al. Management of HIV-infected patients in the intensive care unit. Intensive Care Med. 2020;46:329-42

4. Luna LD, Soares DS, Silva Junior GB, Cavalcante MG, Malveira LR, Meneses GC, et al. Clinical characteristics, outcomes and risk factors for death among critically ill patients with HIVrelated acute kidney injury. Rev Inst Med Trop Sao Paulo. 2016;58:52

5. Jotwani V, Li Y, Grunfeld C, Choi AI, Shlipak MG. Risk factors for ESRD in HIV-infected individuals: traditional and HIVrelated factors. Am J Kidney Dis. 2012;59:628-35.

6. Halle MP, Edjomo AM, Fouda H, Djantio H, Essomba N, Ashuntantang GE. Survival of HIV infected patients on maintenance hemodialysis in Cameroon: a comparative study. BMC Nephrol. 2018;19:166.

7. Wyatt CM. Kidney Disease and HIV infection. Top Antivir Med. 2017;25:13-6.

8. Azoulay E, Castro N, Barbier F. Critically ill patients with HIV: 40 years later. Chest. 2019;157:293-309.

9. Coelho LE, Ribeiro SR, Veloso VG, Grinsztejn B, Luz PM. Hospitalization rates, length of stay and in-hospital mortality in 
a cohort of HIV infected patients from Rio de Janeiro, Brazil. Braz J Infect Dis. 2017;21:190-5.

10. Brasil. Ministério da Saúde. Secretaria de Vigilância em Saúde. HIV/Aids: 2019. Bol Epidemiol. 2019;N. Esp:1-70. [cited 2021 Mar 19]. Available from: http://www.aids.gov.br/pt-br/ pub/2019/boletim-epidemiologico-de-hivaids-2019

11. Autenrieth CS, Beck EJ, Stelzle D, Mallouris C, Mahy M, Ghys P. Global and regional trends of people living with HIV aged 50 and over: estimates and projections for 2000-2020. PLoS One. 2018;13:e0207005.

12. Alencar RA, Ciosak IS. O diagnóstico tardio e as vulnerabilidades dos idosos vivendo com HIV/AIDS. Rev Esc Enferm USP. 2014;49:229-35.

13. Ghidei L, Simone MJ, Salow MJ, Zimmerman KM, Paquin AM, Skarf LM, et al. Aging, antiretrovirals, and adherence: a meta analysis of adherence among older HIV-infected individuals. Drugs Aging. 2013;30:809-19.

14. Souza PN, Miranda EJ, Cruz R, Forte DN. Cuidados paliativos no paciente com HIV/AIDS internado na unidade de terapia intensiva. Rev Bras Ter Intensiva. 2016;28:301-9.

15. Silva DR, Menegotto DM, Schulz LF, Gazzana MB, Dalcin PT. Mortality among patients with tuberculosis requiring intensive care: a retrospective cohort study. BMC Infect Dis. 2010;10:54.

16. Ferreira MD, Neves CP, Souza AB, Beraldi-Magalhães F, Migliori GB, Kritski AL, et al. Predictors of mortality among intensive care unit patients coinfected with tuberculosis and HIV. J Bras Pneumol. 2018;44:118-24.

17. Smit M, Brinkman K, Geerlings S, Smit C, Thyagarajan K, Van Sighem A, et al. Future challenges for clinical care of an ageing population infected with HIV: a modelling study. Lancet Infect Dis. 2015; 15:810-8.

18. Shivakoti R, Gupte N, Tripathy S, Poongulali S, Kanyama C, Berendes $\mathrm{S}$, et al. Inflammation and micronutrient biomarkers predict clinical HIV treatment failure and incident active TB in HIV-infected adults: a case-control study. BMC Med. 2018;16:161.

19. Mdodo R, Frazier EL, Dube SR, Mattson CL, Sutton MY, Brooks JT, et al. Cigarette smoking prevalence among adults with HIV compared with the general adult population in the United States: cross-sectional surveys. Ann Intern Med. 2015;162:33544.
20. Lopes JA, Melo MJ, Raimundo M, Fragoso A, Antunes F. Longterm risk of mortality for acute kidney injury in HIV-infected patients: a cohort analysis. BMC Nephrol. 2013;14:32.

21. Yang HY, Beymer MR, Suen SC. Chronic disease onset among people living with HIV and AIDS in a large private insurance claims dataset. Sci Rep. 2019;9:18514.

22. Vincent B, Timsit JF, Auburtin M, Schortgen F, Bouadma L, Wolff M, et al. Characteristics and outcomes of HIV-infected patients in the ICU: impact of the highly active antiretroviral treatment era. Intensive Care Med. 2004;30:859-66.

23. Croda J, Croda MG, Neves A, Santos SS. Benefit of antiretroviral therapy on survival of human immunodeficiency virusinfected patients admitted to an intensive care unit. Crit Care Med. 2009;37:1605-11.

24. Chiang HH, Hung CC, Lee CM, Chen HY, Chen MY, Sheng WH, et al. Admissions to intensive care unit of HIV-infected patients in the era of highly active antiretroviral therapy: etiology and prognostic factors. Crit Care. 2011;15:R202.

25. Berry SA, Fleishman JA, Moore RD, Gebo KA. Trends in reasons for hospitalization in a multisite United States cohort of persons living with HIV, 2001-2008. J Acquir Immune Defic Syndr. 2012;59:368-75.

26. Long LC, Fox MP, Sauls C, Evans D, Sanne I, Rosen SB. The high cost of HIV-positive inpatient care at an urban hospital in Johannesburg, South Africa. Plos One. 2016;11:e0148546.

27. Dickson SJ, Batson S, Copas AJ, Edwards SG, Singer M, Miller RF. Survival of HIV-infected patients in the intensive care unit in the era of highly active antiretroviral therapy. Thorax. 2007;62:964-8.

28. Huang L, Quartin A, Jones D, Havlir DV. Intensive care of patients with HIV infection. N Engl J Med. 2006;355:173-81.

29. Andrade HB, Shinotsuka CR, Silva IR, Donini CS, Li HY, Carvalho FB, et al. Highly active antiretroviral therapy for critically ill HIV patients: a systematic review and metaanalysis. PLoS One. 2017;12:e0186968.

30. Azevedo LN, Ximenes RA, Monteiro P, Montarroyos UR, Miranda-Filho DB. Factors associated to modification of first-line antiretroviral therapy due to adverse events in people living with HIV/AIDS. Braz J Infect Dis. 2020;24:65-72.

31. McLaughlin MM, Guerrero AJ, Merker A. Renal effects of nontenofovir antiretroviral therapy in patients living with HIV. Drugs Context. 2018;7:212519. 